SAND99-0563J.

REI-10, Jena, Germany, July 1999

\title{
THE MECHANICAL PROPERTIES OF ALUMINA FILMS FORMED BY PLASMA DEPOSITION AND BY ION IRRADIATION OF SAPPHIRE.
}

\section{J. C. Barbour, J. A. Knapp, D. M. Follstaedt, T. M. Mayer, K. G. Minor, and D. L. Linam}

Sandia National Laboratories, Albuquerque, NM 87185-1056.

\section{Abstract}

This paper examines the correlation between mechanical properties and the density, phase, and hydrogen content of deposited alumina layers, and compares them to those of sapphire and amorphous alumina synthesized through ion-beam irradiation of sapphire. Alumina films were deposited using electron beam evaporation of aluminum and co-bombardment with $\mathrm{O}_{2}{ }^{+}$ions $(30-230 \mathrm{eV})$ from an electron cyclotron resonance (ECR) plasma. The $\mathrm{H}$ content and phase were controlled by varying the deposition temperature and the ion energy. Sapphire was amorphized at $84 \mathrm{~K}$ by irradiation with $\mathrm{Al}$ and $\mathrm{O}$ ions (in stoichiometric ratio) to a defect level of $4 \mathrm{dpa}$ in order to form an amorphous layer $370 \mathrm{~nm}$ thick. Nanoindentation was performed to determine the elastic modulus, yield strength and hardness of all materials. Sapphire and amorphized sapphire have a higher density and exhibit superior mechanical properties in comparison to the deposited alumina films. Density was determined to be the primary factor affecting the mechanical properties, which showed only a weak correlation to the hydrogen content.

Corresponding author: J.C. Barbour, MS 1056, Sandia National Laboratories, Albuquerque, NM 87185-1056, USA, 1-505-844-5517, 1-505-844-7775 (fax), jcbarbo@sandia.gov

PACS: 61.82Ms, 62.20.-x

Keywords: Alumina; Nanoindentation; Irradiation; Plasma-deposited; Yield Strength 


\section{DISCLAIMER}

This report was prepared as an account of work sponsored by an agency of the United States Government. Neither the United States Government nor any agency thereof, nor any of their employees, make any warranty, express or implied, or assumes any legal liability or responsibility for the accuracy, completeness, or usefulness of any information, apparatus, product, or process disclosed, or represents that its use would not infringe privately owned rights. Reference herein to any specific commercial product, process, or service by trade name, trademark, manufacturer, or otherwise does not necessarily constitute or imply its endorsement, recommendation, or favoring by the United States Government or any agency thereof. The views and opinions of authors expressed herein do not necessarily state or reflect those of the United States Government or any agency thereof. 


\section{DISCLAIMER}

Portions of this document may be illegible in electronic image products. Images are produced from the best available original document. 


\section{Introduction}

Ion implantation is known to modify the surface properties of materials and is often used to improve mechanical performance [1-4]. However, limitations imposed by the ionimplantation range have motivated an alternative approach for making thick layers with improved properties by combining deposition of films with ion irradiation. Deposited films, however, often have poorer mechanical properties than implanted bulk substrates [5-9].

Implantation of sapphire at room temperature creates line defects which may contribute to strengthening, or introduces impurity atoms which can cause strengthening of the sapphire surface through solid solution or precipitation strengthening. In fact, McHargue [2] showed that implanting $\mathrm{Cr}$ at room temperature increases the hardness of (0001) sapphire by a factor of 1.55 . For samples implanted at $77 \mathrm{~K}$, the hardness initially increased with the formation of defects up to the point where the sapphire was amorphized and then the hardness decreased markedly to $60 \%$ of the hardness for unimplanted sapphire ( $\sim 30 \mathrm{GPa})$. In comparison, Zywitzki et al. $[5,9]$ and Schneider et al. [8] both determined that the hardness of deposited alumina films was strongly dependent upon the deposition temperature and phase formed. The crystalline phases (gamma, kappa, and theta phases) had hardnesses between 19 and $22 \mathrm{GPa}$, whereas the amorphous phase had a lower hardness. Finally, Dienst [10] examined the mechanical properties of neutron-irradiated single crystal and polycrystalline $\alpha$-alumina and found that a small reduction in the elastic modulus and a decrease in fracture strength were correlated to a volume increase (density decrease) under irradiation. Ion irradiation of bulk sapphire is also known to produce a volume expansion $[11,12]$, creating a residual compressive stress in the implanted layer. An improved understanding of the relationship between the structural properties and 
mechanical properties of thin film alumina in comparison to bulk sapphire is needed in order to improve the properties of the films for wear resistant coatings.

This paper is the first to compare the mechanical properties of irradiated bulk alumina to deposited alumina films in an effort to identify unifying principles governing their mechanical properties. Several differences can be found between bulk alumina and thin alumina films, including: the phase [5, 8-9], density and hydrogen content [12]. These three parameters were varied systematically to determine if any one of these correlates strongly with changes in the elastic modulus $(\mathrm{E})$, yield strength $(\mathrm{Y})$, and hardness $(\mathrm{H})$.

\section{Experiment}

Samples were made by two ion-beam techniques: 1) plasma deposited films, using energetic $\mathrm{O}_{2}{ }^{+}$ions from an ECR oxygen plasma, and 2) ion-implanted sapphire layers, using $\mathrm{Al}$ and $\mathrm{O}$ ions in a stoichiometric 2:3 ratio. Both thin $(<300 \mathrm{~nm})$ and thick $(>800 \mathrm{~nm})$ ECR films were deposited on (100) $\mathrm{Si}$ substrates in order to evaluate the substrate effects on the determination of the film properties. Alumina films were deposited using electron beam evaporation of $\mathrm{Al}$ at $0.4 \mathrm{~nm} / \mathrm{s}$ and co-bombardment with $\mathrm{O}_{2}{ }^{+}$ions from an ECR plasma generated using 100 Watts of $2.45 \mathrm{GHz}$ microwave power. The deposition chamber base pressure was 0.6$5 \times 10^{-8}$ Torr and during deposition an $\mathrm{O}_{2}$ flow rate of $2.5 \mathrm{sccm}$ produced a background $\mathrm{O}_{2}$ pressure of $5-7 \times 10^{-5}$ Torr $\mathrm{O}_{2}$.

The $\mathrm{H}$ content and phase of the samples were controlled by varying the deposition temperature and the ion energy. Hydrogen is introduced into the samples during deposition by interaction of the reactive oxygen plasma with hydrogen adsorbed on the chamber walls. Earlier, we had shown that separately increasing the ion energy or temperature $\left(<400^{\circ} \mathrm{C}\right)$ decreased the $\mathrm{H}$ 
content while forming the amorphous phase [13]. Simultaneously increasing the ion energy $\left(\mathrm{E}\left(\mathrm{O}_{2}{ }^{+}\right) \geq 170 \mathrm{eV}\right)$ and the temperature $\left(\geq 400^{\circ} \mathrm{C}\right)$ forms the crystalline $\gamma$-alumina phase (fcc). For these experiments, amorphous alumina samples with a high $\mathrm{H}$ content were deposited at 145 $170^{\circ} \mathrm{C}$ with $30 \mathrm{eV} \mathrm{O}{ }_{2}^{+}$ions, and amorphous alumina samples with a low $\mathrm{H}$ content were deposited at $400^{\circ} \mathrm{C}$ with $30 \mathrm{eV} \mathrm{O}_{2}^{+}$ions. Gamma-alumina films with a low $\mathrm{H}$ content were deposited at $400^{\circ} \mathrm{C}$ with $230 \mathrm{eV} \mathrm{O}_{2}^{+}$ions. The hydrogen content of the $\gamma$ phase was decreased further by vacuum annealing portions of these samples at $850^{\circ} \mathrm{C}$ for one hour at a pressure of $1 \times 10^{-8}$ Torr. The thermal release of hydrogen from deposited alumina samples only occurs above $400^{\circ} \mathrm{C}$ [14], and annealing near $800^{\circ} \mathrm{C}$ for $3-5$ hours [15] only causes slight grain coarsening of $\gamma$ alumina without a transformation to sapphire.

Single crystal $(1 \overline{1} 02)$ sapphire samples were ion implanted with $\mathrm{Al}$ and $\mathrm{O}$ using the energies and fluences shown in Table I in order to form a $370 \mathrm{~nm}$ thick amorphous alumina layer in the surface region. The ions were incident at an angle of $5^{\circ}$ relative to the surface normal. The samples were held at $84 \mathrm{~K}$ for the entire time required to perform all of the implantations in order to avoid thermal annealing between changing implantation from $\mathrm{Al}$ to $\mathrm{O}$. (The thick amorphous layer could be formed only by eliminating this thermal recovery.) The fluences were chosen to cause a uniform level of damage in the sample of approximately 4 dpa up to a depth of about $330 \mathrm{~nm}$ as determined from a TRIM-92 calculation using displacement energies for $\mathrm{Al}$ and $\mathrm{O}$ of $20 \mathrm{eV}$ and $70 \mathrm{eV}$, respectively. The TRIM simulations indicate the surface $(\leq 10 \mathrm{~nm})$ received a damage level less than $2.5 \mathrm{dpa}$ for this set of implantation conditions, while a damage level greater than 2.5 dpa was produced out to $370 \mathrm{~nm}$. A damage tail extending to a depth of about $470 \mathrm{~nm}$ was also indicated. These fluences maintained a stoichiometric implantation profile in which the additional $\mathrm{Al}$ and $\mathrm{O}$ added to the sample at any given depth was in the ratio 2 
$\mathrm{Al} / 3 \mathrm{O}$. The addition of implanted $\mathrm{Al}$ and $\mathrm{O}$ increased the number of atoms in the upper $430 \mathrm{~nm}$ by approximately 0.43 at. $\%$.

The phase and microstructure of the samples were determined using transmission electron microscopy (bright-field imaging, dark-field imaging, and electron diffraction). Also, the samples were analyzed using $2.8 \mathrm{MeV} \mathrm{He}^{+}$Rutherford Backscattering Spectrometry (RBS) to determine the $\mathrm{O}$ and $\mathrm{Al}$ composition and to determine the areal density (number of atoms per unit area) of the deposited films. The $\mathrm{H}$ content was measured using $24 \mathrm{MeV} \mathrm{Si}^{+5}$ elastic recoil detection (ERD). The mass density of deposited films was calculated from the thickness, which was determined from variable angle spectroscopic ellipsometry (VASE), and from the areal density. The density of the implanted sapphire layer was determined by measuring the thickness from TEM analyses and measuring the step-height between implanted and unimplanted regions with atomic force microscopy (AFM).

The mechanical properties were measured with ultra-low load nanoindentation using the Continuous Stiffness Measurement (CSM) technique [16]. A nanoindentation measurement is accomplished by pushing a small three-sided Berkovich-shaped diamond indenter into the sample and then withdrawing it, recording the force required as a function of position. The measured force as a function of depth during loading is characteristic of the resistance of the sample to deformation, including both elastic and plastic changes, and during unloading the decrease of force with depth is controlled by the elastic response. For a layer on a substrate, the values of $\mathrm{E}$ and $\mathrm{H}$ derived from a conventional analytical approach are due to the combined mechanical properties of the layer and substrate. Therefore, finite element analysis is required to accurately determine the mechanical properties of the layer alone [17]. This is especially true for 
thin films on hard substrates. For the CSM technique, an AC modulation is superimposed on the applied load and the response of the sample gives the contact stiffness as a function of depth.

Finite element analysis was used to model the loading (force versus depth) and stiffness (the slope of the force versus depth curve for instantaneous unloading) data to determine $\mathrm{E}, \mathrm{Y}$, and $\mathrm{H}$ of the layers and films. A detailed description of the nanoindentation and finite-element determination of mechanical properties can be found in reference [17]. Ten indentations were done on each sample and the results averaged. Whenever a sample has deformed plastically, an indentation impression is retained by the material; scanning electron microscopy (SEM) was used to image the residual indentation impressions.

\section{Results}

As stated above, the phase and microstructure of the samples were characterized using TEM. Results for deposited amorphous and $\gamma$ alumina were presented previously [13], but an example of the ion-beam amorphization of sapphire is worthy of consideration here. Figure 1 is a dark-field TEM micrograph of sapphire amorphized at $84 \mathrm{~K}$, viewed in cross-section along the $[20 \overline{2} \overline{1}]$ zone axis of the sapphire substrate. This image was formed using the $(1 \overline{2} 10)$ sapphire reflection indicated on the diffraction pattern (shown inset). The diffraction pattern shows a diffuse ring characteristic of amorphous alumina in addition to diffraction spots corresponding to sapphire reflections. The dashed circle on the micrograph represents the region from which the diffraction pattern was acquired. This micrograph shows crystallites of residual sapphire extending from the surface (shown at upper left in this figure) to a depth of approximately 20 $\mathrm{nm}$, corresponding to the decreased level of damage found in the TRIM simulations. Crystalline material is nearly absent in the center of the implanted layer and the amorphized region extends 
up to $335 \mathrm{~nm}$ in depth. A region of mixed amorphous and nanometer-sized crystallites is seen in the transition zone between the amorphous region and the sapphire at the surface as well as the sapphire substrate. The dashed line indicates a depth of $370 \mathrm{~nm}$. At depth, the mixed amorphous-nanocrystalline region extends to $425 \mathrm{~nm}$.

Ion-irradiation induced amorphization of sapphire at room temperature requires ion fluences producing damage levels on the order of $100 \mathrm{dpa}$ [18], whereas amorphization at liquid nitrogen temperatures requires damage levels of only a few dpa. For the case of room temperature ion irradiation, the mechanism producing the amorphous phase is suggested to be accumulation of point defects and voids causing a density reduction which makes the crystalline sapphire unstable relative to the amorphous phase. In fact, both the high and low temperature amorphization are accompanied by a density reduction as evidenced in AFM measurements of our samples exhibiting an expansion of the irradiated layer above the surrounding substrate. The height of this step ( $\Delta \mathrm{t}=30 \mathrm{~nm} \pm 0.6 \mathrm{~nm}$ ) was used to determine the change in density of the irradiated layer, $\rho_{\text {layer, }}$ according to the equation: $\rho_{\text {layer }}=\rho_{\text {sapphire }}\left[1-\left(\Delta t / t_{\text {layer }}\right)\right]+\phi / t_{\text {layer, }}$, where $\phi$ is the total fluence of $\mathrm{Al}$ and $\mathrm{O}$ implanted ions, $\mathrm{t}_{\text {layer }}(370 \mathrm{~nm})$ is the layer thickness measured from the TEM cross-section micrograph (Fig. 1), and the density of sapphire is taken to be the literature value of $3.98 \mathrm{~g} / \mathrm{cm}^{3}$.

Table II summarizes the results of the density determined from VASE analysis and RBS analysis of the deposited films, as well as that of irradiated sapphire. In addition, the hydrogen contents determined from ERD analyses are given. The uncertainty for the thicknesses determined from VASE analysis is $\leq 2 \%$ and the uncertainty for the areal density measured from RBS analysis is $\leq 5 \%$. These uncertainties can make substantial differences in the absolute values determined for the densities, but the relative accuracy in comparing the densities 
measured in the same manner is better than $1 \%$. Therefore, the trends determined from the densities calculated in this manner are sufficiently accurate to determine the relative dependence of the mechanical properties on density.

Typical force and stiffness versus depth curves for the different types of samples with relatively thick layers are shown in figure 2. Each curve is an average over ten indentations. The data shown as open circles was collected from the $1081 \mathrm{~nm}$ thick amorphous film deposited at $145^{\circ} \mathrm{C}$ and containing 5.77 at. $\% \mathrm{H}$. The data shown as + symbols was collected from the 873 nm thick $\gamma$-alumina film deposited at $400^{\circ} \mathrm{C}$ and containing 0.23 at. $\% \mathrm{H}$. The data shown as filled circles was collected from the $370 \mathrm{~nm}$ thick amorphized sapphire containing 0.02 at. $\% \mathrm{H}$, and the data shown as open triangles was collected from the (1 $\overline{1} 02)$ sapphire substrate containing $\leq 0.01$ at. $\% \mathrm{H}$ (lower detectability limit). A qualitative examination of the data immediately shows that a simple relationship between phase and mechanical properties does not exist. The stiffness versus depth curves show that amorphous alumina can have both a larger and smaller apparent elastic modulus than the crystalline $\gamma$ alumina depending upon the method of preparation. Further, the $\gamma$ alumina has a significantly lower stiffness than the sapphire even though both are crystalline phases. Similarly, the force versus depth curves indicate that the plastic behavior of amorphous alumina can vary greatly and show no direct correlation to the phase (amorphous versus crystalline).

The solid lines drawn through each set of data in Fig. 2 are the best fit simulation of the elastic and plastic response of the layer/substrate combination modeled using the finite element analysis code ABAQUS. In this process, the stress-strain behavior of the substrate (sapphire or $\mathrm{Si}$ ) is determined first, and then used as a known quantity in the simulation of the alumina layer/substrate combination. The stress-strain behavior (elastic modulus and yield strength) is 
then varied for the layer to obtain the best fit to both the loading data and the stiffness data, simultaneously. For these samples, a work hardening rate of zero was used, as is appropriate for ceramic materials. The value of intrinsic hardness, $\mathrm{H}$, for each material was determined by separate simulations of "bulk" samples [17], using the values determined for $\mathrm{E}$ and $\mathrm{Y}$. In this way, $\mathrm{E}, \mathrm{Y}$ and $\mathrm{H}$ for all of the samples were determined and are tabulated in Table II. The values of $\mathrm{E}, \mathrm{Y}$, and $\mathrm{H}$ determined for different thicknesses of the same type materials were the same, showing that the modeling correctly accounts for the effect of the substrate. The value obtained for $E$ from $(1 \overline{1} 02)$ sapphire in this experiment $(502 \mathrm{GPa})$ is in good agreement with $E$ obtained [19] for alumina whiskers (496.2 GPa), and the sapphire yield strength (14.98 GPa) is just below the fracture strength reported for those whiskers $(15.2 \mathrm{GPa})$.

SEM was used to image the residual indent impressions and this analysis demonstrated that the samples were all deforming plastically during nanoindentation without forming extensive cracks. Therefore, the finite element modeling is valid for determining a yield strength from the acquired nanoindentation data and for comparing the results from the different samples.

Table II shows a strong correlation between the mechanical properties and the alumina density, but a poor correlation between the mechanical properties and the phase of the alumina. Further, the mechanical properties appear only slightly correlated to the hydrogen content. In order to better examine the correlation between the mechanical properties and the density, the E, $\mathrm{H}$, and $\mathrm{Y}$ are plotted as a function of density in figures 3-5. The error bars shown in these figures were determined by combining the statistical uncertainties in the raw data with the quality of the simulation fits [17]. The strong linear dependence upon density of the elastic modulus, yield strength, and hardness is remarkably independent of phase. Finally, the magnitude of change in the mechanical properties with a small percentage change in density is also remarkable. A $25 \%$ 
change in density causes nearly a factor of 3 change in $\mathrm{E}$, a factor of 4 change in $\mathrm{Y}$, and a factor of 3.5 change in $\mathrm{H}$.

\section{Discussion}

Alumina forms many different crystalline phases with similar local atomic environments and differing densities. The phase-independent mechanical properties probably reflect the fact that the mechanical properties are determined to a large extent by accumulation of free volume resulting from bond-angle distortions which should vary in a continuous fashion with density $\left(\mathrm{Al}^{3+}-\mathrm{O}^{2-}\right.$ spacing) rather than phase. Alumina is a highly ionic material and thus the local bonding should depend strongly on the electrostatic forces holding the crystal together. These forces should change in a smooth continuous fashion, as indicated by the linear dependence, but the low density alumina must also come to a balance in electrostatic forces for densities far from true equilibrium in the hexagonal phase. This balance of electrostatic forces may be accommodated with some amount of electrostatic screening caused by incorporating free volume and/or hydrogen.

The density of a sample may change by accumulation of point defects that agglomerate and create large quantities of open volume. These may be introduced during growth of the deposited films or by post-synthesis ion irradiation for the amorphized sapphire. In either case, the hydrogen content probably reflects the willingness of the matrix to accept a charged hydrogen which screens electrostatic forces at work when the ionic $\mathrm{Al}^{3+}$ and $\mathrm{O}^{2-}$ are displaced far from equilibrium. The introduction of $\mathrm{H}$ is expected to impact the density (possibly stabilizing very-low-density amorphous alumina), but point defects and free volume also may be accumulated without the incorporation of hydrogen. The mechanical properties depend upon 
density much more strongly and directly than they depend upon $\mathrm{H}$ content, suggesting that density is the primary factor in determining the mechanical properties.

The fact that alumina can be formed with a $25 \%$ change in density and produce a factor of 4 difference in yield strength has profound consequences for the use of alumina as a wearresistant coating and as a dispersion strengthening precipitate. Clearly, the greatest wear resistance and precipitation strengthening would occur for the most dense alumina. Also, $\mathrm{Al}$ corrosion passivation layers are generally low-density, high-H content alumina layers and this work indicates that these layers should have poor mechanical strength and be more easily susceptible to rupture during corrosion than a dense alumina coating.

\section{Acknowledgements}

We would like to thank George Arnold, J.C. McCallum, and Sam Myers for useful technical discussions, and Gary Petersen and Mike Moran for technical assistance. This work was supported by the DOE Office of Basic Energy Sciences. Sandia is operated by Lockheed Martin Company, for the U.S. DOE under contract DE-AC04-94AL85000.

\section{References}

[1] C.J. McHargue, G.C. Farlow, C.W. White, B.R. Appleton, P. Angelini, and H. Naramoto, Nucl. Instrum. and Meth. B10/11 (1985) 569.

[2] C.J. McHargue, Nucl. Instrum.and Meth. B19/20 (1987) 797.

[3] T. Hioki, A. Itoh, M. Ohkubo, S. Noda, H. Doi, J. Kawamoto, and O. Kamigaito, J. Mater. Sci. 21 (1986) 1321.

[4] S.J. Bull and T.F. Page, J. Mater. Sci. 23 (1988) 4217. 
[5] O. Zywitzki, G. Hoetzsch, F. Fietzke, and K. Goedicke, Surface and Coatings Tech. 82 (1996) 169.

[6] V.A.C. Haanappel, D.v.d. Vendel, H.S.C. Metselaar, H.D. van Corbach, T. Fransen, and P.J. Gellings, Thin Solid Films 254 (1995) 153.

[7] N.G. Chechenin, J. Bøttiger, and J.P. Krog, Thin Solid Films 261 (1995) 219.

[8] J.M. Schneider, W.D. Sproul, and A. Matthews, Surface and Coatings Tech. 94 (1997) 179.

[9] O. Zywitzki and G. Hoetzsch, Surface and Coatings Tech. 94 (1997) 303.

[10] W. Dienst, J. Nucl. Mater. 211 (1994) 186.

[11] G.B. Kreft and E.P. EerNisse, J. Appl. Phys. 49 (1978) 2725.

[12] G.W. Arnold, Mat. Sci. and Engineering A 253 (1998) 71.

[13] D.A. Marshall, J.C. Barbour, D.M. Follstaedt, A.J. Howard, and R.J. Lad, Mat. Res. Soc. Symp. Proc. $\underline{403}$ (1996) 235.

[14] J.C. Barbour and B.G. Potter, Mat. Res. Soc. Symp. Proc. $\underline{504}$ (1998) 387.

[15] C.W. White, C.J. McHargue, P.S. Sklad, L.A. Boatner, and G.C. Farlow, Mat. Sci. Rep. 4 (1989) 57.

[16] W.C. Oliver and G.M. Pharr, J. Mater. Res. 7 (1992) 1564.

[17] J.A. Knapp, D.M. Follstaedt, S.M. Myers, J.C. Barbour, and T.A. Friedmann, J. Appl. Phys. 85 (1999) 1460.

[18] E.D. Specht, D.A. Walko, and S.J. Zinkle, Nucl. Instrum.and Meth. B84 (1994) 323.

[19] R.W. Hertzberg, Deformation and Fracture Mechanics of Engineering Materials, (John Wiley and Sons, NY, 1976) p. 233.

\section{Figure Captions}


1. Dark-field, cross-section TEM micrograph of an amorphized sapphire layer. The diffraction pattern shown at bottom right was acquired from approximately the region indicated by the dished circle.

2. Typical indentation loading and stiffness curves acquired using the continuous stiffness method. The data are for: open circles -amorphous $\mathrm{Al}_{2} \mathrm{O}_{3}$ deposited at $145^{\circ} \mathrm{C},+$ symbols $-\gamma$ $\mathrm{Al}_{2} \mathrm{O}_{3}$ deposited at $400^{\circ} \mathrm{C}$, filled circles - amorphized sapphire, and open triangles - sapphire substrate. The solid lines are the best fit simulations of the loading process, modeled using the finite element analysis code ABAQUS.

3. Variation in the elastic modulus as a function of density. This figure includes data for all three alumina phases examined: amorphous, gamma, and sapphire. A 25\% change in density causes nearly a factor of 3 change in $\mathrm{E}$.

4. Variation in yield strength as a function of density. A $25 \%$ change in density causes a factor of 4 change in $Y$.

5. Variation in the layer hardness as a function of alumina density. A $25 \%$ change in density produces a factor of 3.5 change in $\mathrm{H}$. 
Tables

TABLE I: Implantation Conditions

\begin{tabular}{|c|c|c|c|c|c|c|}
\hline $\begin{array}{l}\text { Implant } \\
\text { species }\end{array}$ & $\begin{array}{c}\text { Energy } \\
(\mathrm{keV})\end{array}$ & $\begin{array}{c}\begin{array}{c}\text { Fluence } \\
\left(\text { ions } / \mathrm{cm}^{2}\right)\end{array} \\
\end{array}$ & & $\begin{array}{l}\text { Implant } \\
\text { species }\end{array}$ & $\begin{array}{c}\text { Energy } \\
(\mathrm{keV})\end{array}$ & $\begin{array}{c}\begin{array}{c}\text { Fluence } \\
\left(\text { ions } / \mathrm{cm}^{2} \text { ) }\right.\end{array} \\
\end{array}$ \\
\hline $\mathrm{Al}$ & 320 & $5.143 \times 10^{15}$ & 2. & $\mathrm{O}$ & 360 & $2 \times 10^{15}$ \\
\hline $\mathrm{Al}$ & 180 & $1.286 \times 10^{15}$ & 4. & $\mathrm{O}$ & 275 & $4 \times 10^{15}$ \\
\hline $\mathrm{Al}$ & 110 & $1 \times 10^{15}$ & 6. & $\mathrm{O}$ & 220 & $1.55 \times 10^{15}$ \\
\hline $\mathrm{Al}$ & 65 & $7.14 \times 10^{13}$ & 8. & $\mathrm{O}$ & 150 & $2.15 \times 10^{15}$ \\
\hline $\mathrm{Al}$ & 30 & $7.14 \times 10^{13}$ & 10. & $\mathrm{O}$ & 90 & $1.4 \times 10^{15}$ \\
\hline 11. & 55 & $2 \times 10^{14}$ & 12. & $\mathrm{O}$ & 30 & $1.1 \times 10^{14}$ \\
\hline
\end{tabular}

TABLE II: Synthesis Conditions and Resultant Properties

\begin{tabular}{l|c|c|c|c|c} 
Sample Description & Density & At. \% H & E (GPa) & Y (GPa) & H (GPa) \\
\hline Virgin $(1102)$ Sapphire Substrate & 3.98 & $\leq 0.01 \%$ & 502 & 14.98 & 33.7 \\
\hline $\begin{array}{l}370 \mathrm{~nm} \text { amorphized sapphire by } \\
84 \mathrm{~K} \mathrm{Al}+\mathrm{O} \text { implant, no anneal }\end{array}$ & 3.662 & $0.02 \%$ & 366 & 11.62 & 26.2 \\
\hline $\begin{array}{l}181 \mathrm{~nm} \text { deposited amorphous } \\
\text { alumina/(100)Si, } \mathrm{T}_{\text {dep }}=400^{\circ} \mathrm{C}\end{array}$ & 3.171 & $\leq 0.01 \%$ & 214 & 5.24 & 13.0 \\
\hline $\begin{array}{l}173 \mathrm{~nm} \text { deposited gamma } \\
\text { alumina/(100)Si, } \mathrm{T}_{\text {dep }}=405^{\circ} \mathrm{C}\end{array}$ & 3.314 & $\leq 0.01 \%$ & 208 & 6.30 & 14.7 \\
\hline $\begin{array}{l}\text { Sample above, annealed } \\
850^{\circ} \mathrm{C} 1 \mathrm{hr} .\end{array}$ & 3.509 & $\leq 0.01 \%$ & 292 & 9.84 & 22.0 \\
\hline $\begin{array}{l}873 \mathrm{~nm} \text { deposited gamma } \\
\text { alumina } /(100) \mathrm{Si}, \mathrm{T}_{\text {dep }}=400^{\circ} \mathrm{C}\end{array}$ & 3.351 & $0.23 \%$ & 277 & 7.88 & 18.6 \\
$\begin{array}{l}\mathrm{Sample} \text { above, annealed } \\
850^{\circ} \mathrm{C} 1 \mathrm{hr} .\end{array}$ & 3.331 & $0.05 \%$ & 291 & 8.12 & 19.2 \\
\hline $\begin{array}{l}896 \mathrm{~nm} \text { deposited amorphous } \\
\text { alumina } /(100) \mathrm{Si}, \mathrm{T}_{\text {dep }}=400^{\circ} \mathrm{C}\end{array}$ & 3.183 & $0.28 \%$ & 187 & 4.45 & 11.1 \\
\hline $\begin{array}{l}250 \mathrm{~nm} \text { deposited amorphous } \\
\text { alumina } /(100) \mathrm{Si}, \mathrm{T}_{\text {dep }}=170^{\circ} \mathrm{C}\end{array}$ & 3.148 & $2.48 \%$ & 177 & 3.73 & 9.6 \\
\hline $\begin{array}{l}1081 \mathrm{~nm} \text { deposited amorphous } \\
\text { alumina } /(100) \mathrm{Si}, \mathrm{T}_{\text {dep }}=145^{\circ} \mathrm{C}\end{array}$ & 3.053 & $5.77 \%$ & 170 & 3.73 & 9.5
\end{tabular}




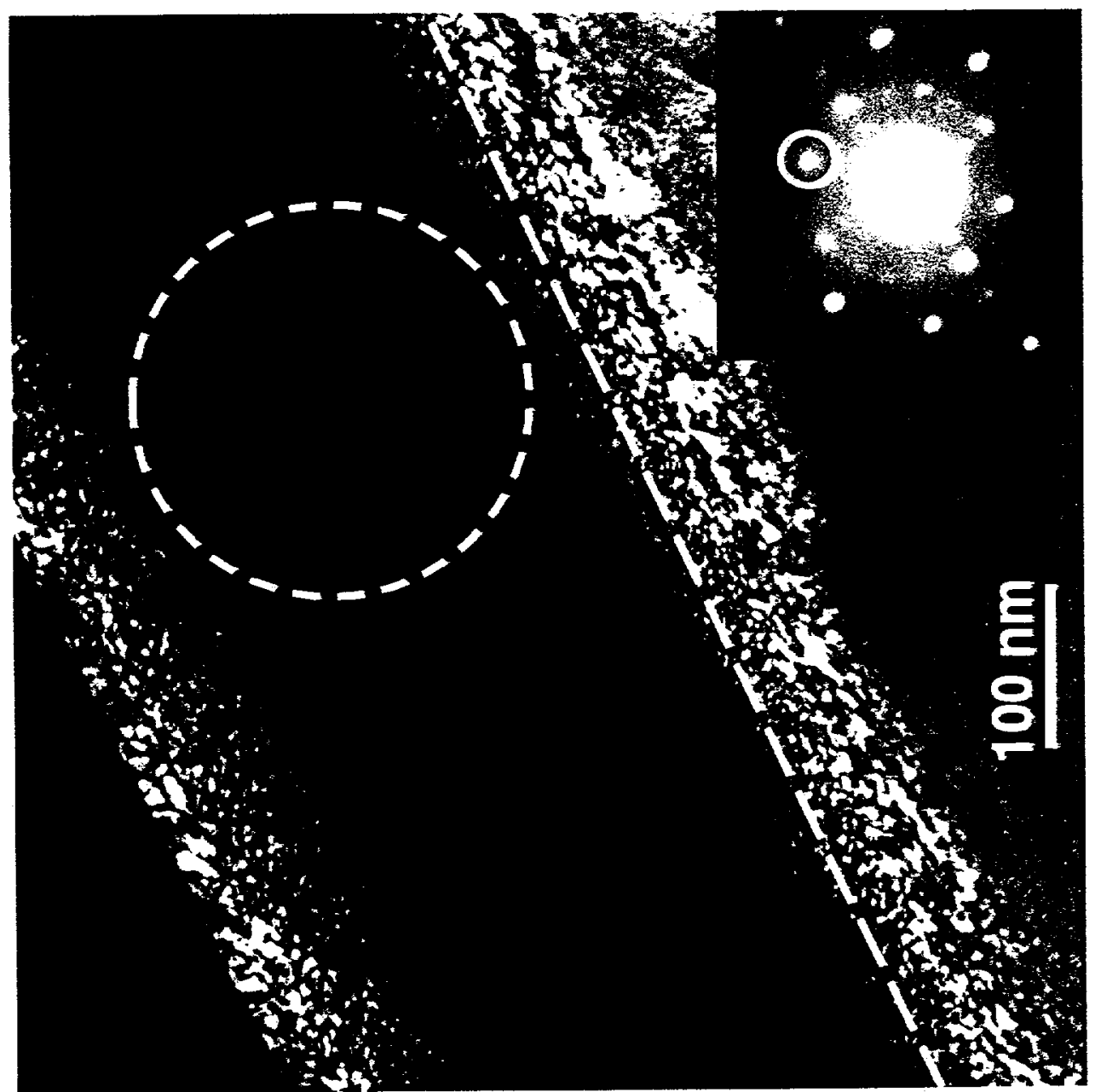



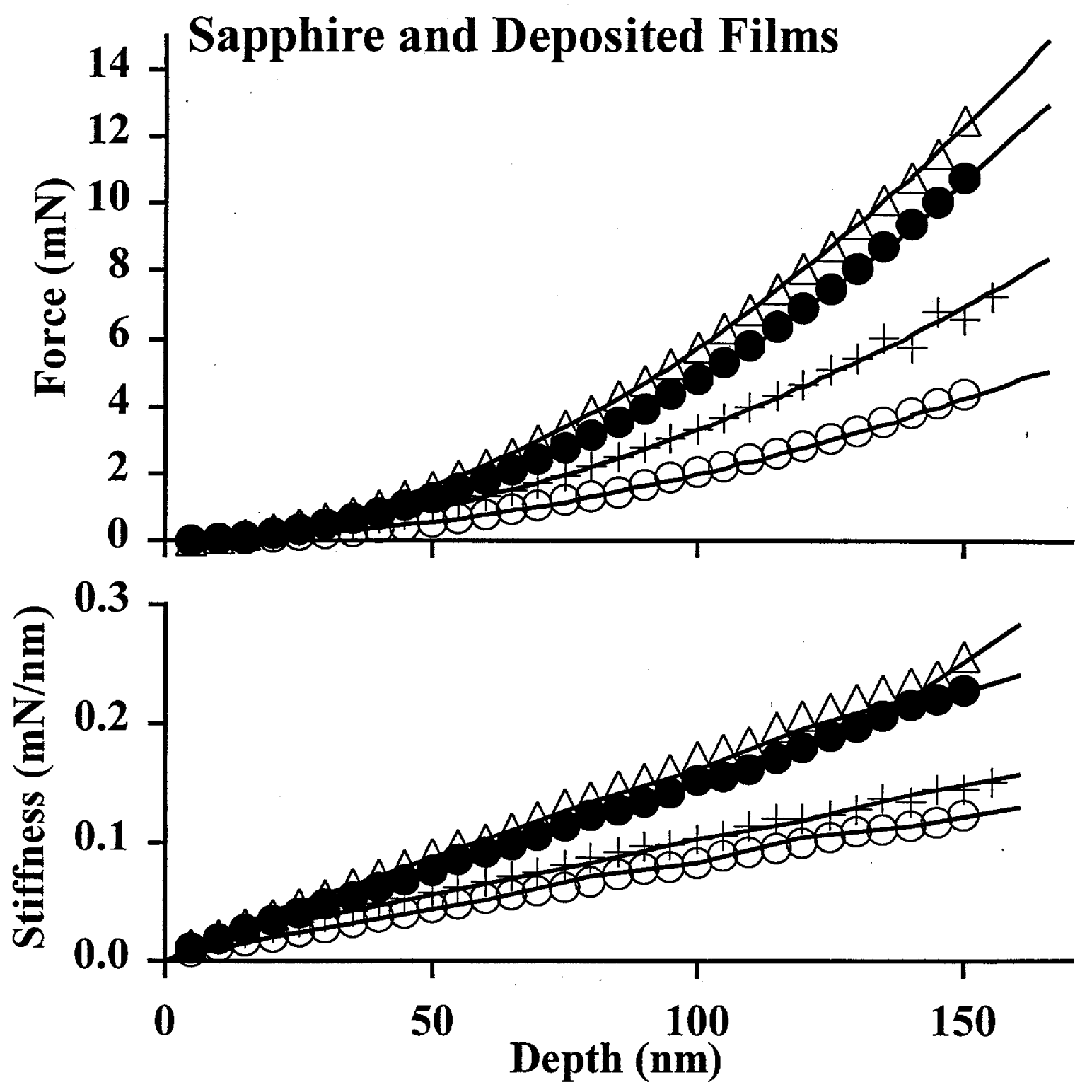

J. C. Barbour et al. Fig. 2 


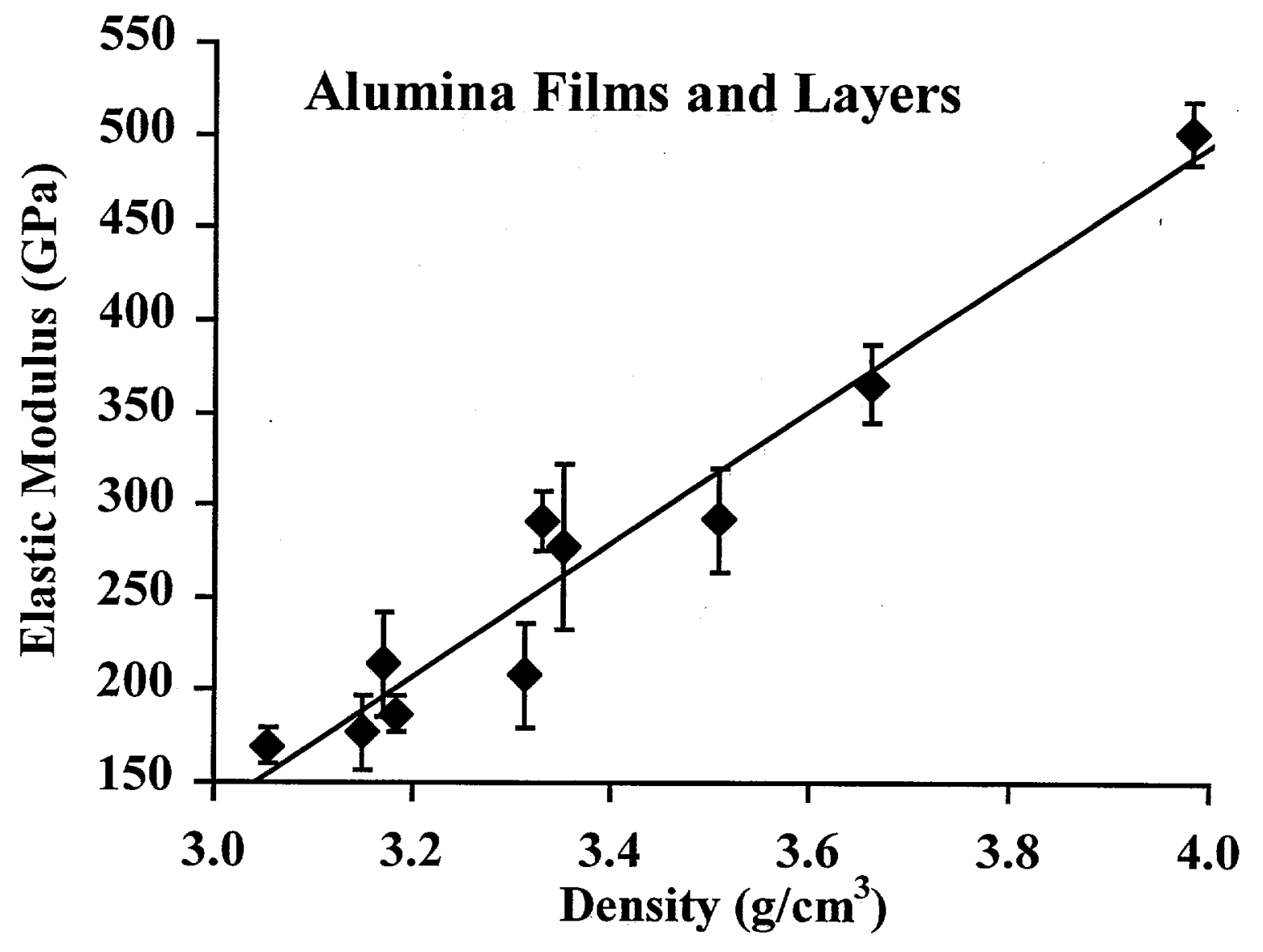

J. C. Barbour et al. Fig. 3 


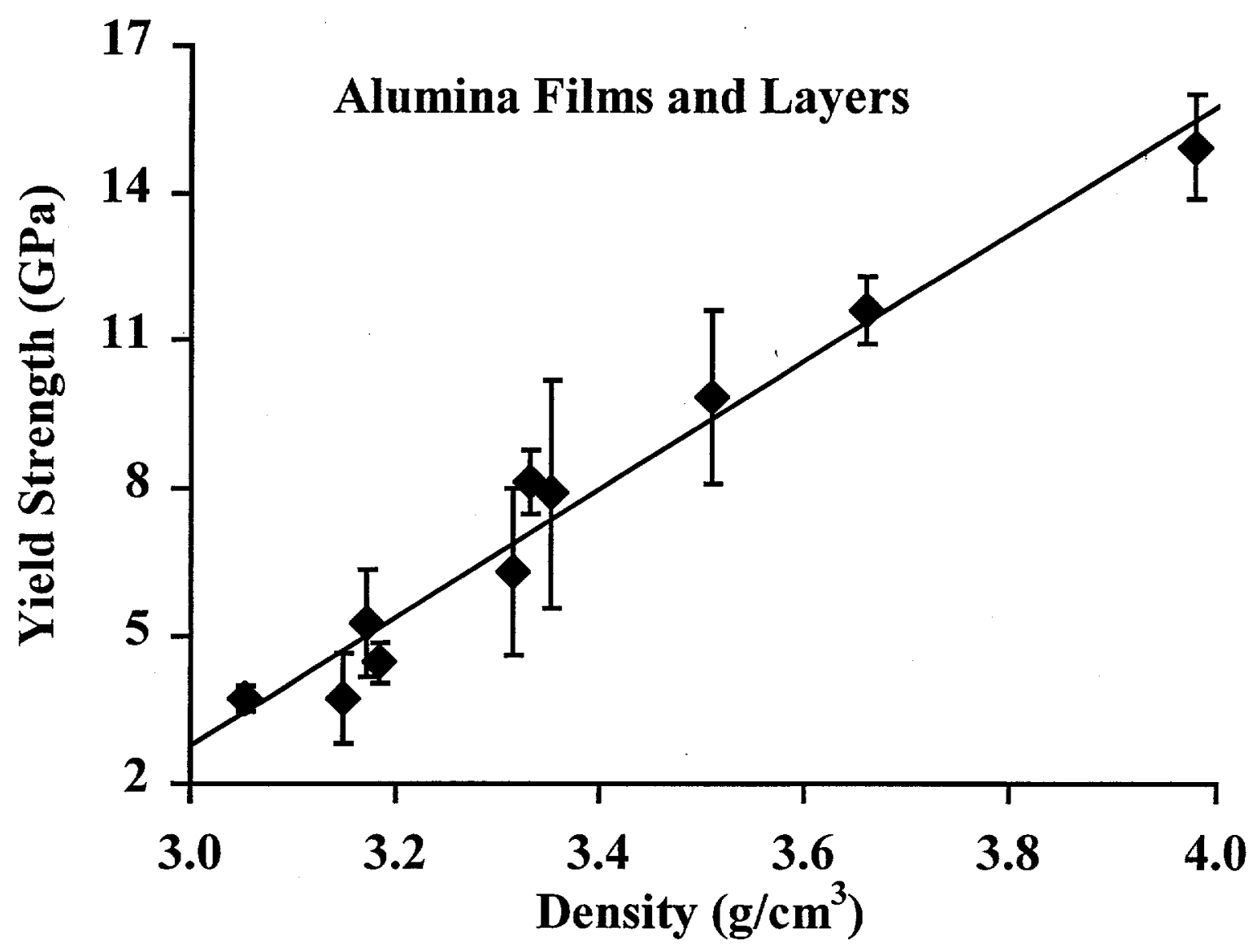

J. C. Barbour et al. Fig. 4 


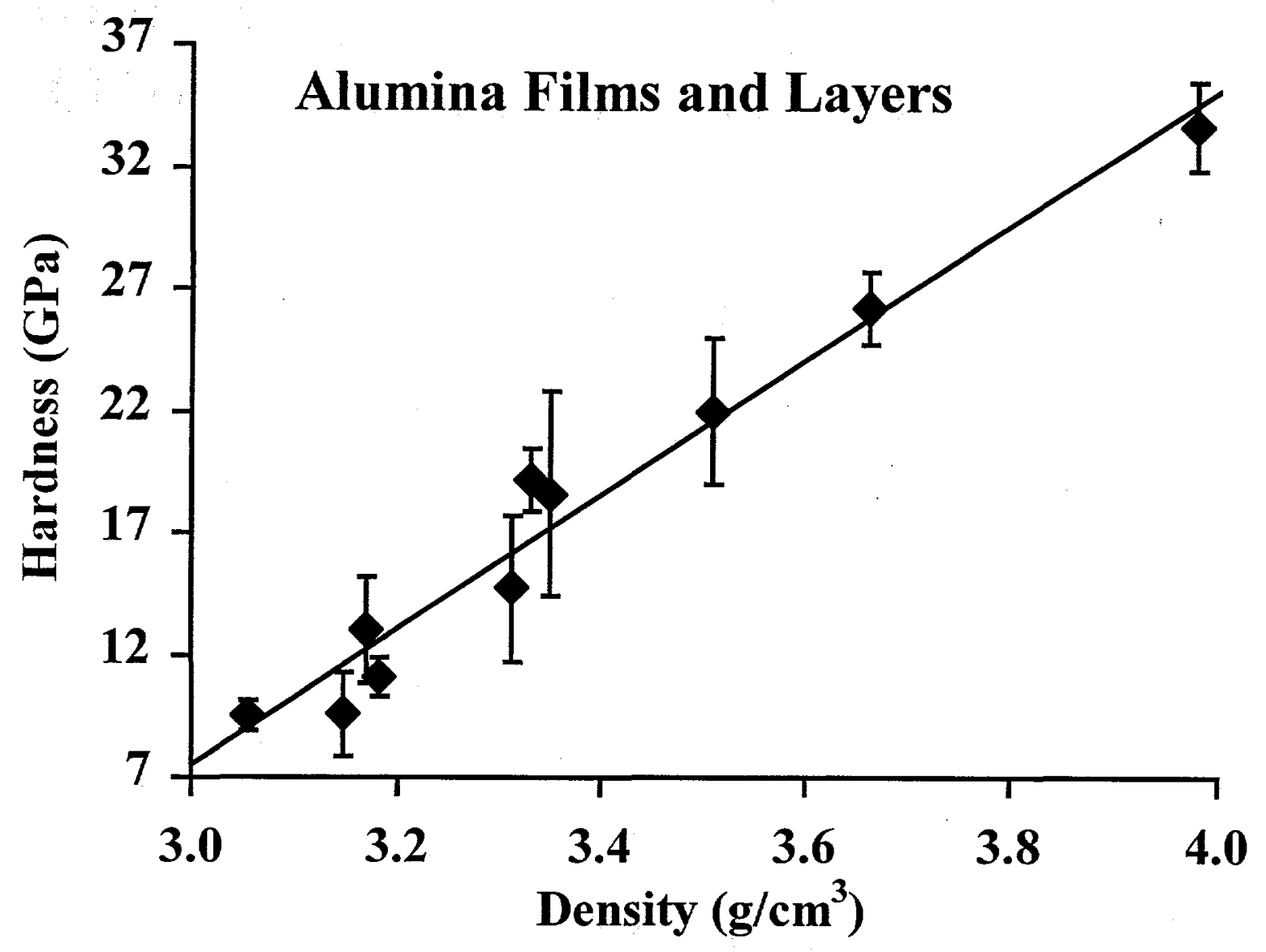

J. C. Barbour et al.

Fig. 5 